مجلة علوم الإنسان والمجتمع............................... عبد العالي دبلة، الباحث: عبد القادر عبان

\title{
تحديات الإدارة الإلكترونية في الجزائر \\ دراسة سوسيولوجية ببلدية الكاليتوس بالعاصمة
}

الأستاذ الدكتور : عبد العالي دبلة، جامعة بسكرة، الجزائر

الباحث: عبد القادر عبان ، جامعة بسكرة، الجزائر

البلدية باعتبارها الإدارة الأقرب إلى المواطن والنواة الرئيسة في المجتمع

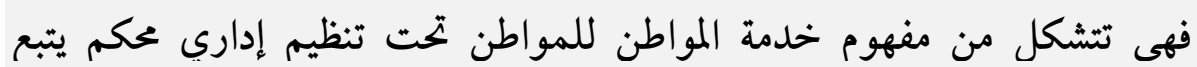

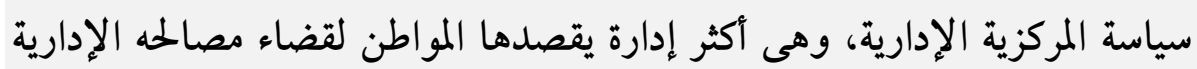

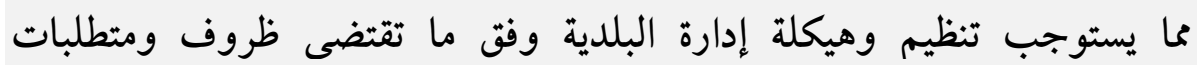

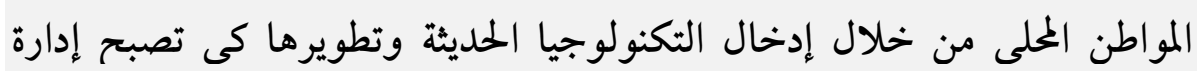
إلكترونية.

\begin{abstract}
:
Municipality represent the closest administration to the citizen and the nucleus major in the community, it made up of the concept of citizen service to the citizen under tight administrative organization follows the administrative central policy, and the municipality is more management destination for citizens to spend administrative interests, which requires organization and restructuring of the municipal administration as required conditions and requirements of the local citizens through the use of modern technology and develop it in order to become an electronic management.
\end{abstract}


مقدّمة:

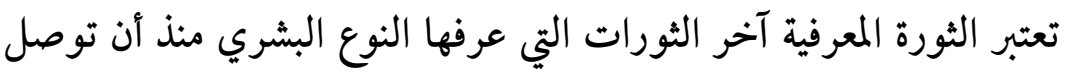

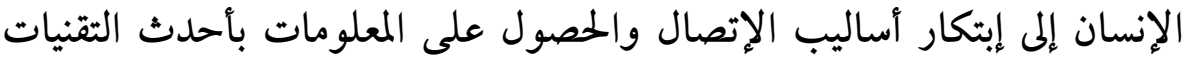

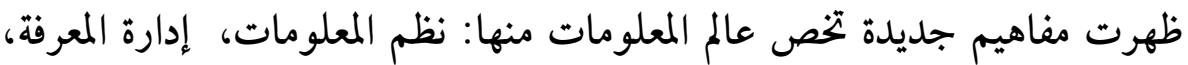

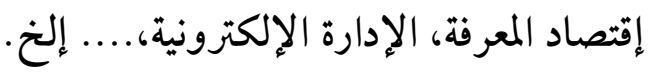

هذه الأخيرة التي تعد آخر ما توصل إليه الفكر الإنساني في بجال الإدارة

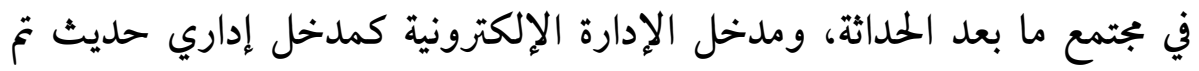

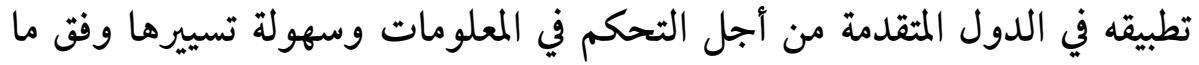

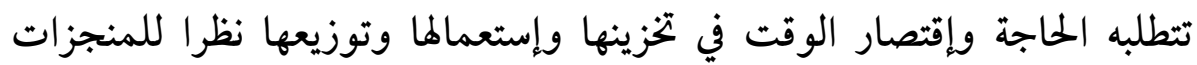

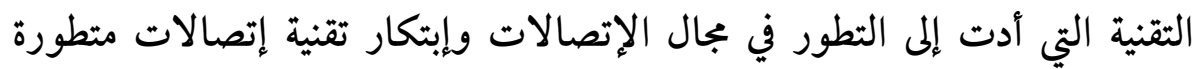
وإستخدام الحاسوب وشبكات الإنترنت في تقديم خدمات الإدارة إلى إلى عملائها

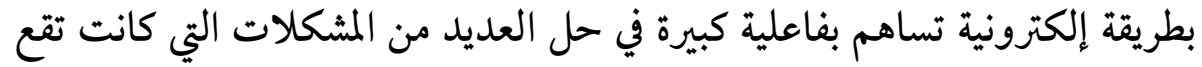

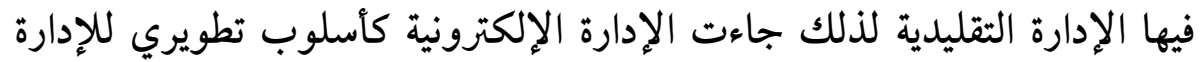

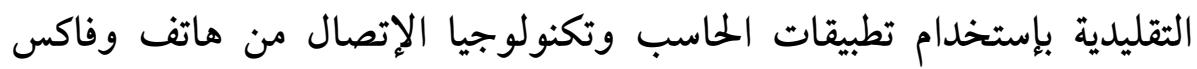

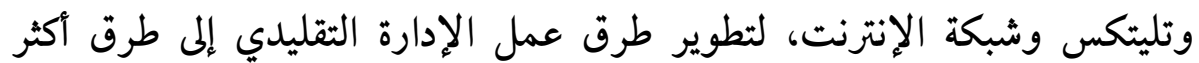
مرونة وفاعلية وتوفير الوقت والجهاديد والتكلفة في الأداء.

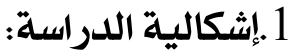

البلدية بإعتبارها إدارة محلية تعمل تحت تنظيم إداري محكم يتبع سياسة

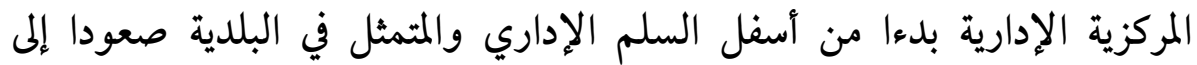

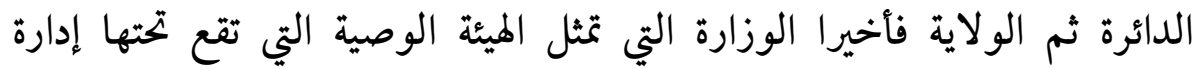

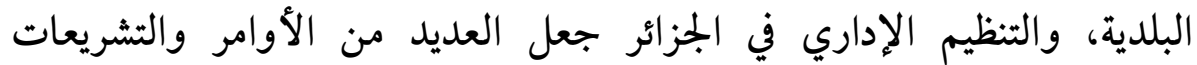

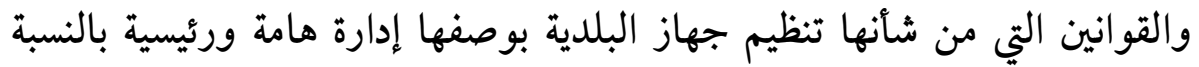

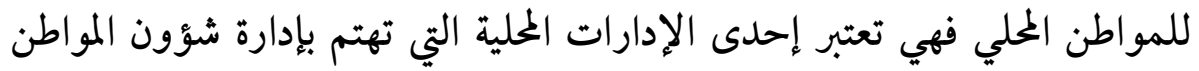

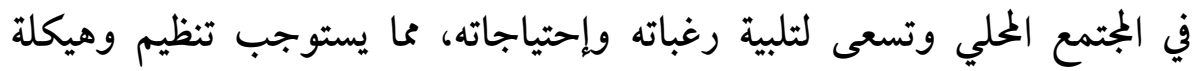




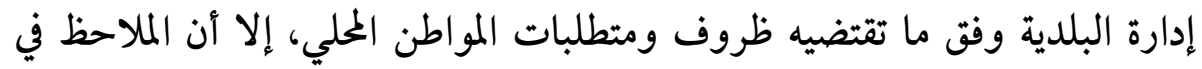

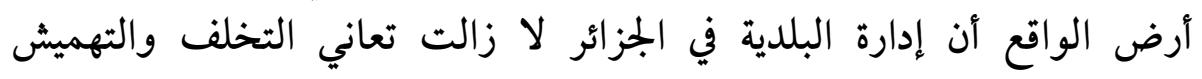

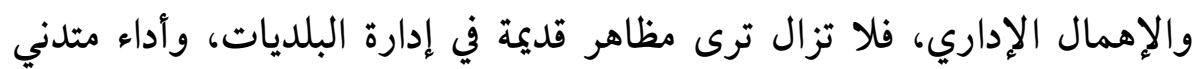

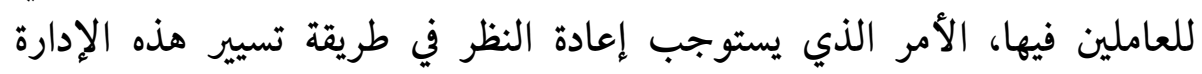

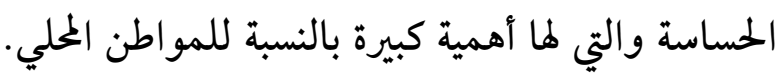

فالبلدية الإلكترونية تستوجب تغييرا جذريا في العمل الإداري التقليدي

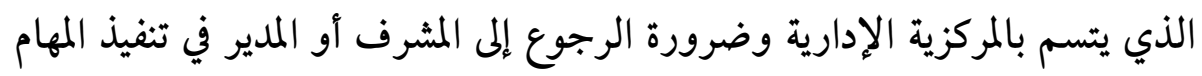

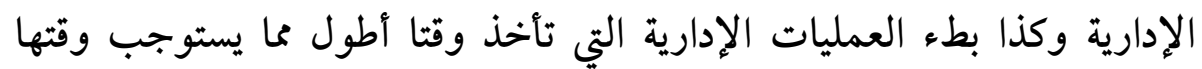

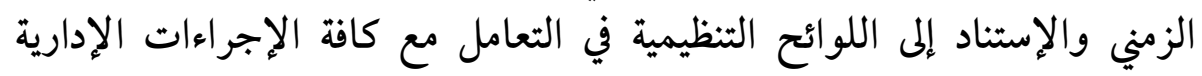

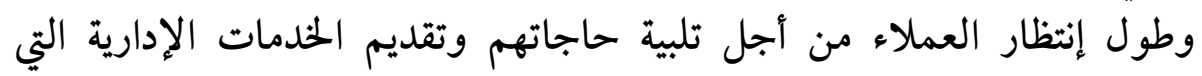

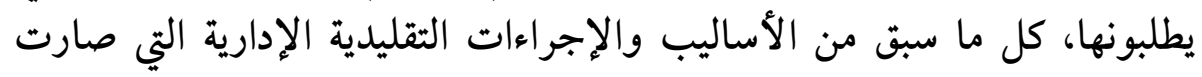

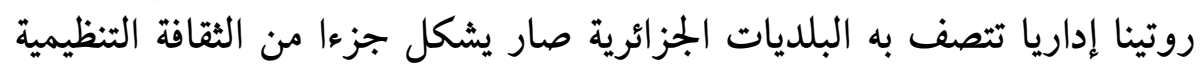

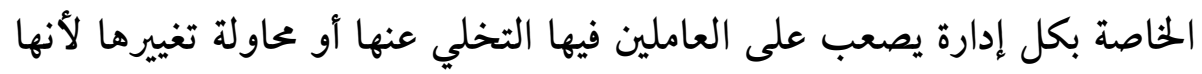

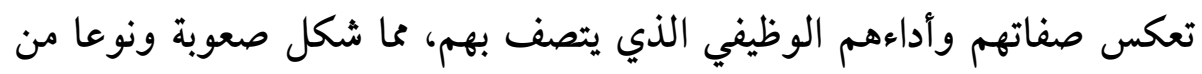
الخلل الوظيفي في تطبيق البلدية الإلكترونية في الجزائر.

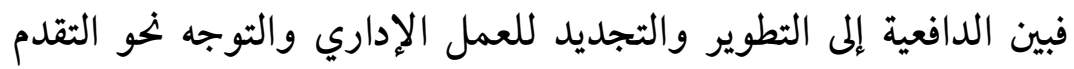

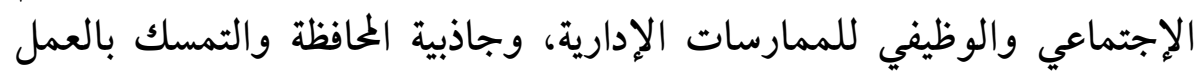

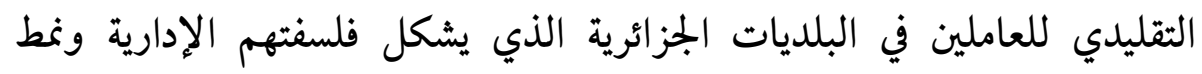

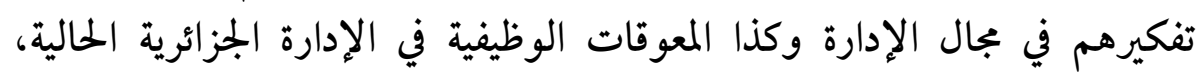

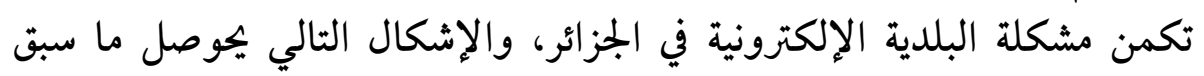

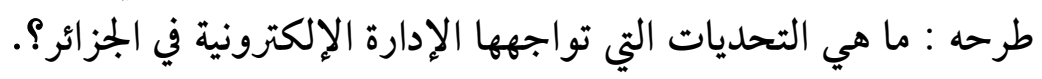
2. فرضيات الدراسة: تعتمد هذه الدراسة على فرضية عامة تتمثل في:

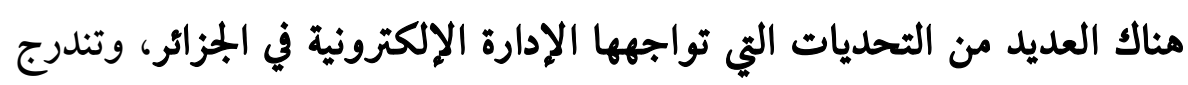
ضمن هذه الفرضية العامة فرضيات جزئية وهي: 
1 هناك إمكانية كبيرة لتطبيق الإدارة الإلكترونية في الجزائر. 2. تساهم الإدارة الإلكترونية بدرجة كبيرة في عصرنة الإدارة التقليدية في الجزائر. 3. هناك علاقة إرتباطية بين درجة تطبيق الإدارة الإلكترونية ودرجة مساهمتها في عصرنة الإدارة التقليدية في الجزائر .

3. مفاهيم الدراسة : تشتمل هذه الدراسة على المفاهيم التالية : 1.الإدارة الإلكترونية : هو مدخل إداري معاصر يحمل في فلسفته مفهوم الإدارة بلا

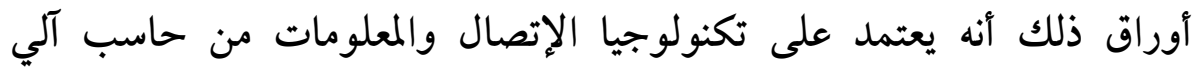
وشبكات إنترنت وفاكس وهاتف في العمليات الإدارية المختلفة من رقابة وتخطيط الإنيط

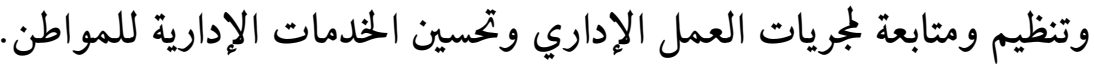
2. البلدية: هي هيئة إدارية منتخبة محليا تتكون من مجلس منتخب ورئيس تنفيذي

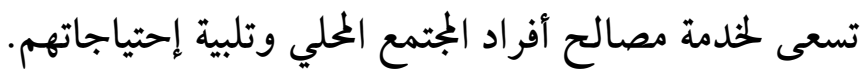

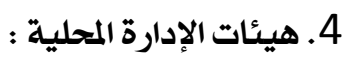

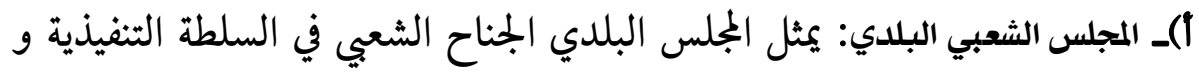

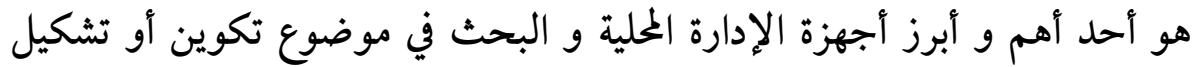

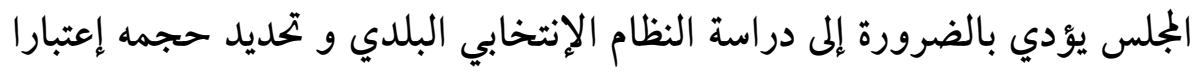

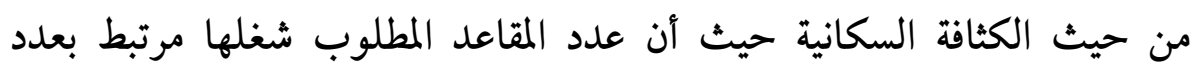

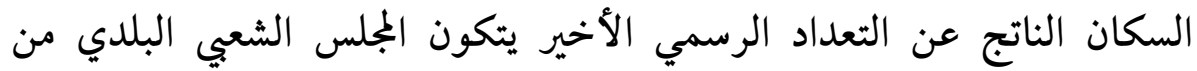
أعضاء يتراوح عددهم بين 7 و 33 منتخبا بلديا حسب التبر عدد سكان سكان البلدية يتم

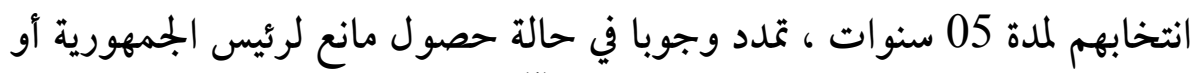

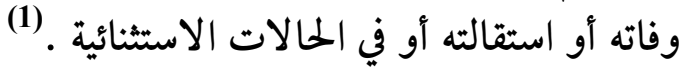

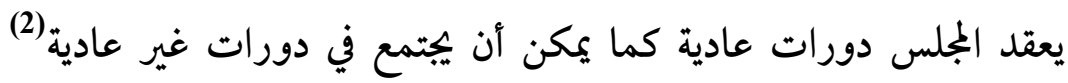

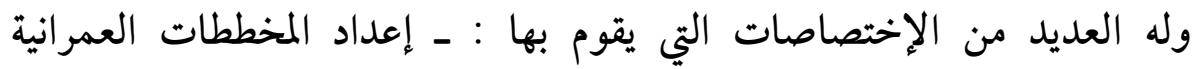

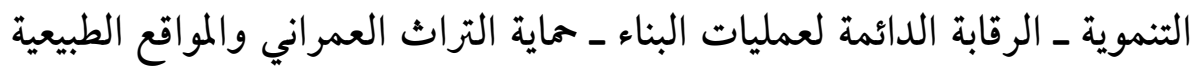


ـ المحافظة على الممتلكات الدينية وصيانة الأوقاف ـ تشجيع العمل الحرفي والثقافي والسياحي ·

ـ محاربة الملوثات وذلك عن طريق تنظيف الأحياء والشوارع والمؤسسات المستقبل

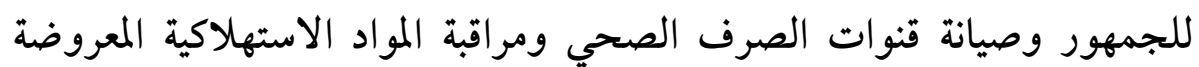

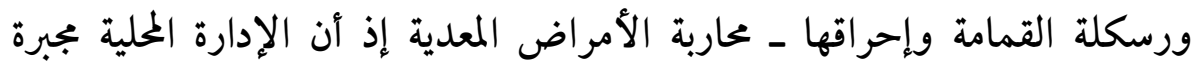

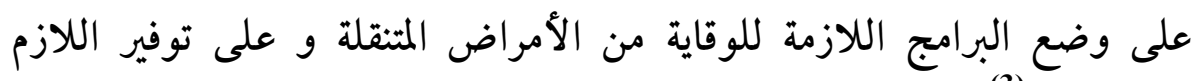
للتصدي لها (3) المبر

ب ) رئيس المجلس الشعبي البلدي: يختار من بين أعضاء القائمة الفائزة و الحاصلة

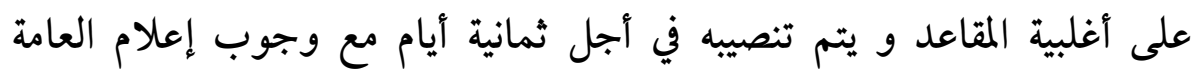

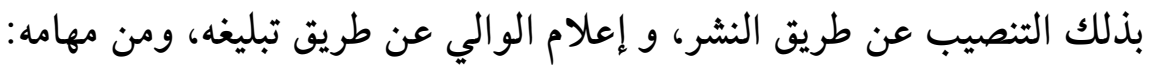
الإشراف على شؤون سير الإدارة المحلية ـ اختيار النواب وتعيين المندوبين ـ تسيير

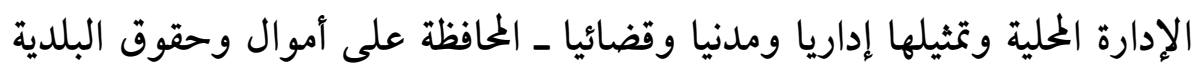

5. 5.طلبات تطبيق الإدارة الإلكزونية : وتشمل مايلي : 1. وضع استراتيجيات وخطط تأسيس الإدارة الإلكترونية . 2. توفر البنية التحتية للإدارة الالكترونية .

3.تطوير التنظيم الإداري والخدمات والمعاملات الحكومية وفق تحول تدرييي .

4. وضع التشريعات القانونية اللازمة لتطبيق الإدارة الالكترونية (5).

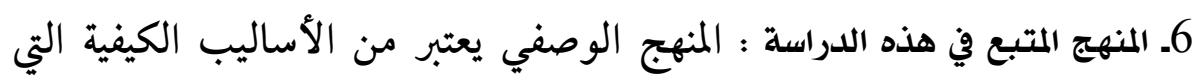

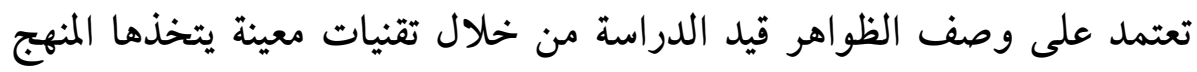

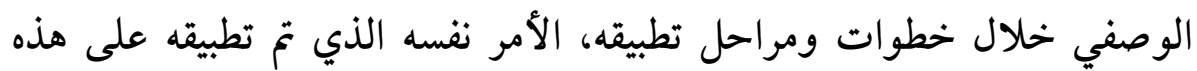

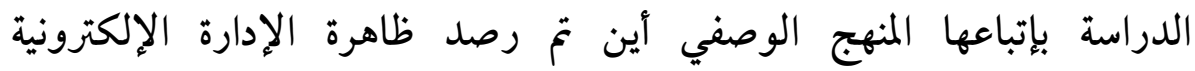

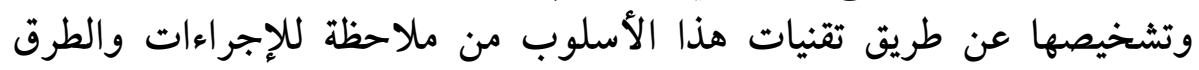


المتبعة وكذا القيام بدليل مقابلة مع بعض المبحوثين من أجل التقصي عن الحقائق

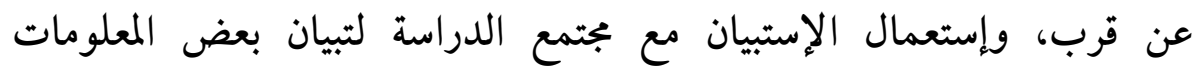
والوقائع التي تخص موضوع والدراسة.

7. عينة الدراسة : لقد تم إختيار عينتين تمثلان جزءا من المجتمع الإحصائي، العينة

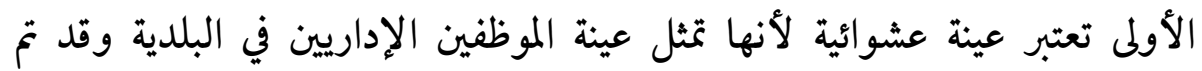

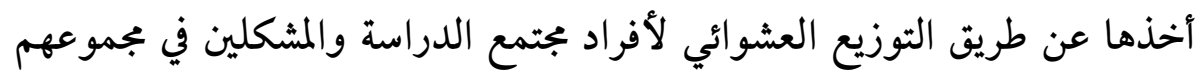

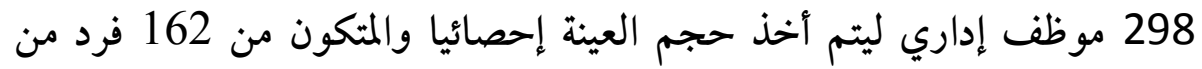

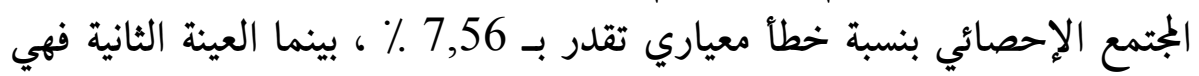

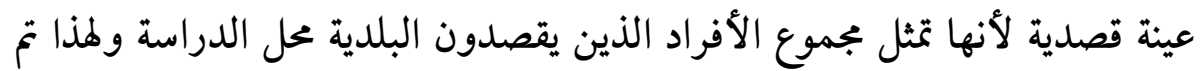
أخذ 32 فرد من الأشخاص الذين يأتون للبلدية محل الدراسة.

8. مقياس الدراسة : تم إستخدام مقياس ليكرت الخماسي من أجل قياس المؤشرات

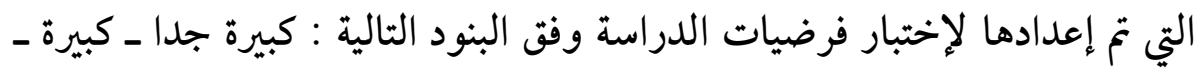

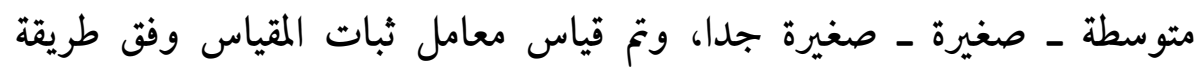

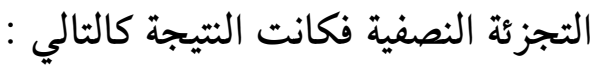

\begin{tabular}{|c|c|c|c|c|}
\hline (T) & الجدولية (T) & (T) & & \\
\hline 0,94 & 21 & 1,72 & 8,57 & $* 04$ \\
\hline
\end{tabular}

$\alpha=0,05$ * دال عند مستوى دلالة *

وبعد تصحيح معامل الثبات وفق طريقة سبيرمان - براون تم الحصول على معامل ثبات قوي جدا، ما يثبت مدى ثبات هذا المقياس في حالة تطبيته

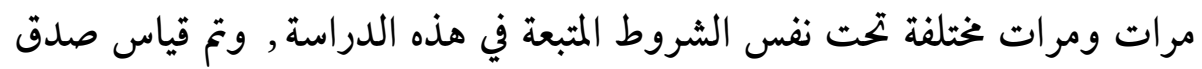

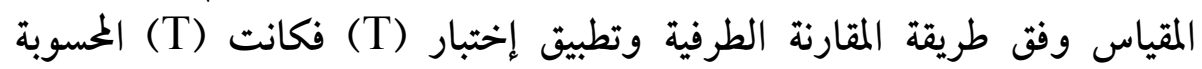
تساوي 6,48 أكبر من (T) الجدولية 1,79 عند مستوى معنوية 
وبدرجة حرية 11، فإننا نرفض الفرض الصفري القائل بعدم صدق الأداة، ونقبل

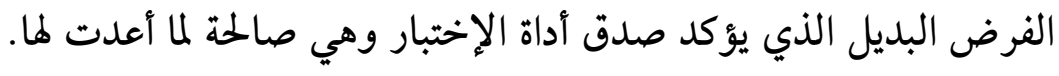
9. - مرض وتحليل نتائج الدراسة : 1- جدول رقم (1) : يتعلق بجنس أفراد عينة الدراسة :

\begin{tabular}{|r|c|r|}
\hline إناث & الجكور \\
\hline 33,33 & 54 & النسبة \\
\hline 66,67 & 108 & \\
\hline 100 & 162 & \\
\hline
\end{tabular}

يبين لنا الجدول أن الفئة الغالبة على هذه العينة هي فئة الإناث ، حيث الإثيث

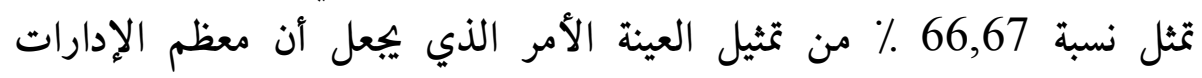

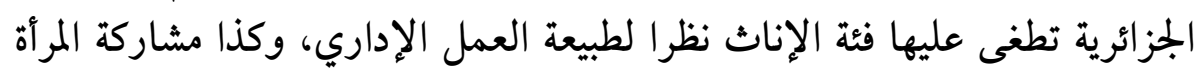

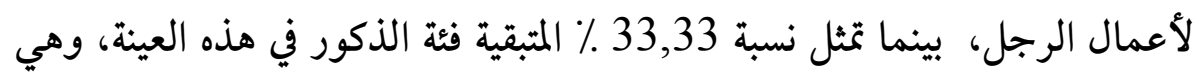

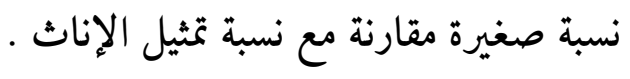


2. جلدول رقهم (2) : يتعلق بسن أفراد عينـة الدراسة

\begin{tabular}{|c|c|c|}
\hline النسبة & & \\
\hline 25,92 & 42 & $28-23$ \\
\hline 37,03 & 60 & $33-28$ \\
\hline 22,23 & 36 & $38-33$ \\
\hline 7,41 & 12 & $43-38$ \\
\hline 7,41 & 12 & $48-43$ \\
\hline 100 & 162 & السجمبة \\
\hline
\end{tabular}

يتبين أن الفئة العمرية الغالبة على عينة الدراسة هي فئة ( 28 ـ 33 )

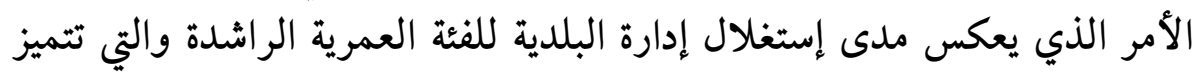

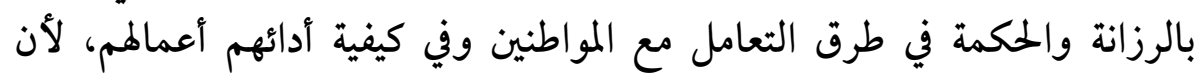

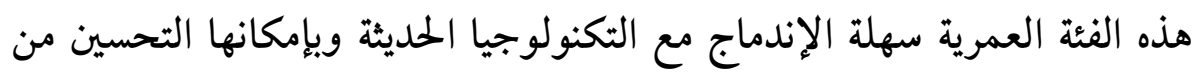

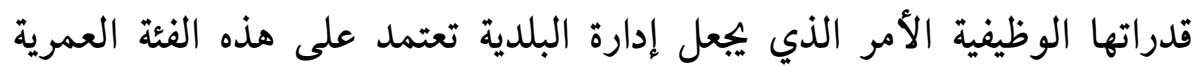

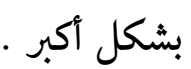

كما تبين أن المتوسط العمري لمذه العينة تمثل في 32,17 أي تقريبا 32

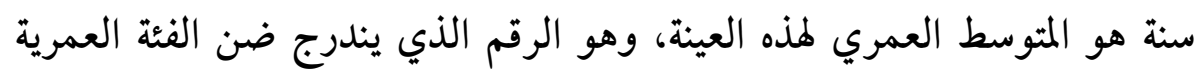

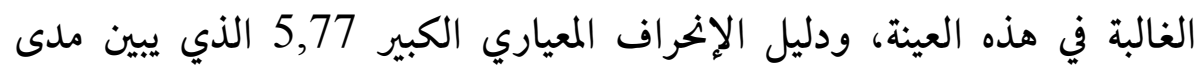
إختلاف الفئات العمرية في هذه العينة وتباين أعمار الموظفين في هذه الإهين البلدية

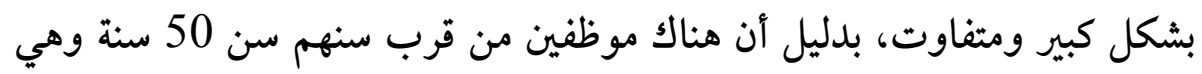

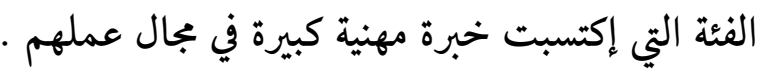


مجلة علوم الإنسان والمجتمع...............................بد العالي دبلة، الباحث: عبد القادر عبان

3. جلدول رقم (3) : يتعلق بالمستوى التعليمي لأفراد عينة الدراسة

\begin{tabular}{|c|c|c|}
\hline النسبة \% & التكرار & المستوى التعليمي \\
\hline 3,72 & 6 & متوسط \\
\hline 37,03 & 60 & ثانوي \\
\hline 22,22 & 36 & تقنى سامى \\
\hline 37,03 & 60 & جامعي \\
\hline 100 & 162 & المجموع \\
\hline
\end{tabular}

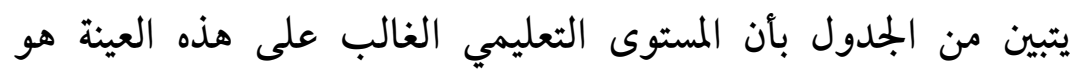

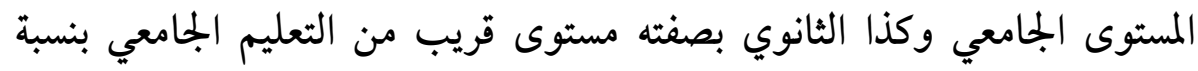

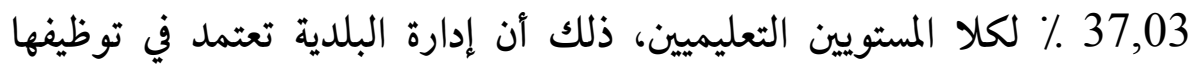

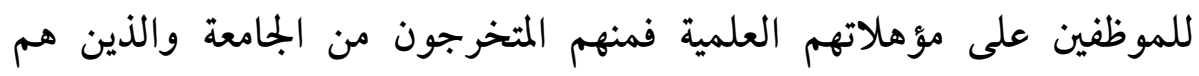

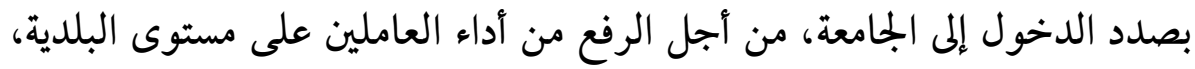

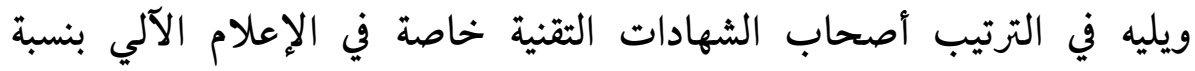

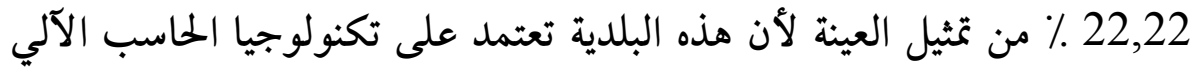

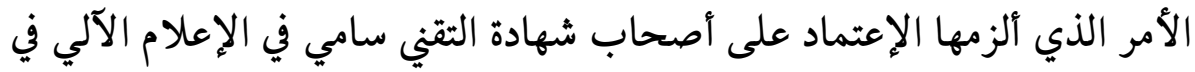
أداء أعمالهم لأنهم يعتبرون العاملين المهرة في إستخدام تكنولوجيا الحاسب الإعب الآلي. 4ـ جدول (4) : يتعلق بلدرجة تطبيق الإدارة الإلكتزونية

\begin{tabular}{|c|c|c|c|c|c|c|c|c|}
\hline T test & $\%$ & Ș & $\mu$ & منعلمة & صغيرة & متوسطة & كبيرة & البند \\
\hline "0.96- & 60,25 & 1,19 & 2,41 & 54 & 30 & 36 & 42 & 01 \\
\hline 9.83 & 77,75 & 0,79 & 3,11 & 0 & 42 & 60 & 60 & 02 \\
\hline 3.85 & 72,25 & 1,29 & 2,89 & 42 & 18 & 18 & 84 & 03 \\
\hline 12.88 & 83,25 & 0,82 & 3,33 & 0 & 36 & 36 & 90 & 04 \\
\hline
\end{tabular}




\section{5}

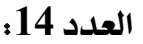

\begin{tabular}{|c|c|c|c|c|c|c|c|c|}
\hline 7.60 & 73,25 & 0,72 & 2,93 & 0 & 48 & 78 & 36 & 05 \\
\hline $1.11^{* *}$ & 60,25 & 1,03 & 2,41 & 42 & 36 & 60 & 24 & 06 \\
\hline 7.41 & 74 & 0,79 & 2,96 & 0 & 54 & 60 & 48 & 07 \\
\hline 5.47 & 51 & 1,07 & 2,04 & 66 & 48 & 24 & 24 & 08 \\
\hline 4.21 & 51,75 & 1,3 & 2,07 & 90 & 12 & 18 & 42 & 09 \\
\hline 8.90 & 44,5 & 1,03 & 1,78 & 90 & 36 & 18 & 18 & 10 \\
\hline 0.69 & 61 & 1,1 & 2,44 & 42 & 42 & 42 & 36 & 11 \\
\hline 0.59 & 64 & 1,29 & 2,56 & 54 & 24 & 24 & 60 & 12 \\
\hline 0.87 & 60,25 & 1,31 & 2,41 & 66 & 18 & 24 & 54 & 13 \\
\hline 0 & 25 & 0 & 1 & 162 & 0 & 0 & 0 & 14 \\
\hline 7.19 & 46,25 & 1,15 & 1,85 & 96 & 18 & 24 & 24 & 15 \\
\hline 4.39 & 52,75 & 1,13 & 2,11 & 72 & 24 & 42 & 24 & 16 \\
\hline $0.65^{* *}$ & 64 & 1,17 & 2,56 & 42 & 36 & 36 & 48 & 17 \\
\hline 0 & 25 & 0 & 1 & 162 & 0 & 0 & 0 & 18 \\
\hline $0.93^{* *}-$ & 60,25 & 1,23 & 2,41 & 54 & 36 & 24 & 48 & 19 \\
\hline 0 & 25 & 0 & 1 & 162 & 0 & 0 & 0 & 20 \\
\hline 2.53 & 56,5 & 1,21 & 2,26 & \multicolumn{5}{|c|}{ المتوسط العام للا } \\
\hline
\end{tabular}

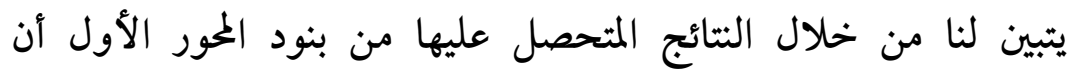

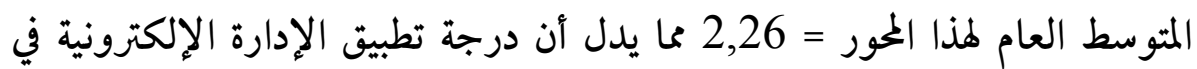

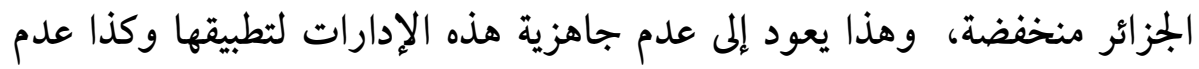
وجود بنية تحتية ومادية وبشرية تساهم بدرجة كبيرة في تطبيق الإدارة الإلكترونية الإنية 
مجلة علوم الإنسان والمجتمع.......................... عبد العالي دبلة، الباحث: عبد القادر عبان

5. جدول رقم(5) : يتعلق بمعوقات تطبيق الإدارة الإلكترونية في الجزائر

\begin{tabular}{|c|c|c|c|c|c|c|c|c|c|}
\hline$T$ test & $\%$ & Ș & $\boldsymbol{\mu}$ & صني & صغيرة & س & كبيرة & كبيرة & البند \\
\hline 10.03 & 78,6 & 1,18 & 3,93 & 12 & 12 & 12 & 66 & 60 & 01 \\
\hline 5.07 & 68,2 & 1,03 & 3,41 & 0 & 42 & 36 & 60 & 24 & 02 \\
\hline 7.75 & 76,2 & 1,33 & 3,81 & 12 & 24 & 18 & 36 & 72 & 03 \\
\hline 4.12 & 66,6 & 1,02 & 3,33 & 6 & 36 & 30 & 78 & 12 & 04 \\
\hline 5.94 & 71,2 & 1,2 & 3,56 & 12 & 24 & 24 & 66 & 36 & 05 \\
\hline 2.69 & 66,6 & 1,56 & 3,33 & 30 & 30 & 18 & 24 & 60 & 06 \\
\hline 2.65 & 66 & 1,44 & 3,3 & 30 & 24 & 12 & 60 & 36 & 07 \\
\hline 15.74 & 37 & 0,93 & 1,85 & 60 & 84 & 6 & 6 & 6 & 08 \\
\hline 2.81 & 54 & 1,36 & 2,7 & 42 & 42 & 12 & 54 & 12 & 09 \\
\hline 8.45 & 77,8 & 1,34 & 3,89 & 18 & 12 & 12 & 48 & 72 & 10 \\
\hline 13.02 & 42,2 & 0,87 & 2,11 & 36 & 90 & 18 & 18 & 0 & 11 \\
\hline 3.68 & 51,2 & 1,52 & 2,56 & 60 & 36 & 6 & 36 & 24 & 12 \\
\hline 4.30 & 69,6 & 1,42 & 3,48 & 24 & 18 & 30 & 36 & 54 & 13 \\
\hline 4.27 & 70,4 & 1,55 & 3,52 & 30 & 24 & 0 & 48 & 60 & 14 \\
\hline 4.66 & 70,4 & 1,42 & 3,52 & 12 & 48 & 6 & 36 & 60 & 15 \\
\hline 5.57 & 72,6 & 1,44 & 3,63 & 18 & 24 & 30 & 18 & 72 & 16 \\
\hline 4.85 & 69,6 & 1,26 & 3,48 & 12 & 24 & 48 & 30 & 48 & 17 \\
\hline 6.42 & 72,6 & 1,25 & 3,63 & 6 & 30 & 42 & 24 & 60 & 18 \\
\hline
\end{tabular}




\section{العدد 14ء................. مارس 2015}

\begin{tabular}{|c|c|c|c|c|c|c|c|c|c|}
\hline 7.85 & 74,8 & 1,2 & 3,74 & 6 & 30 & 18 & 54 & 54 & 19 \\
\hline 9.78 & 78,6 & 1,21 & 3,93 & 12 & 12 & 18 & 54 & 66 & 20 \\
\hline $\mathbf{2 . 4 4}$ & $\mathbf{6 5 , 4}$ & $\mathbf{1 , 4 1}$ & $\mathbf{3 , 2 7}$ & \multicolumn{6}{|c|}{ المتوسط العام للمحور ككل } \\
\hline
\end{tabular}

يتبين لنا من خلال النتائج المتحصل عليها من بنود المحور الثاني أن الن المبان

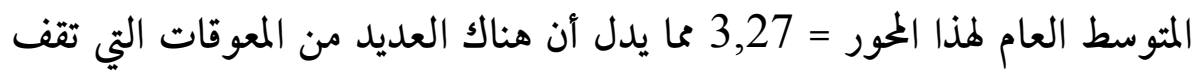

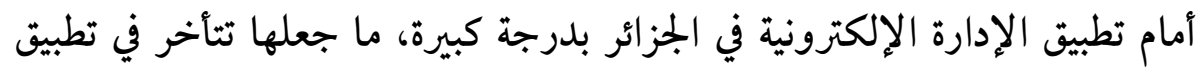
الإدارة الإلكترونية وتتعدد هذه المعوقات إلى بشرية ومادية وتقنية وتشريعية

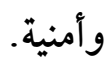

6ـ جدول رقم(6) : يتعلق بدرجة وعي المواطنين حول الإدارة الإلكتزونية

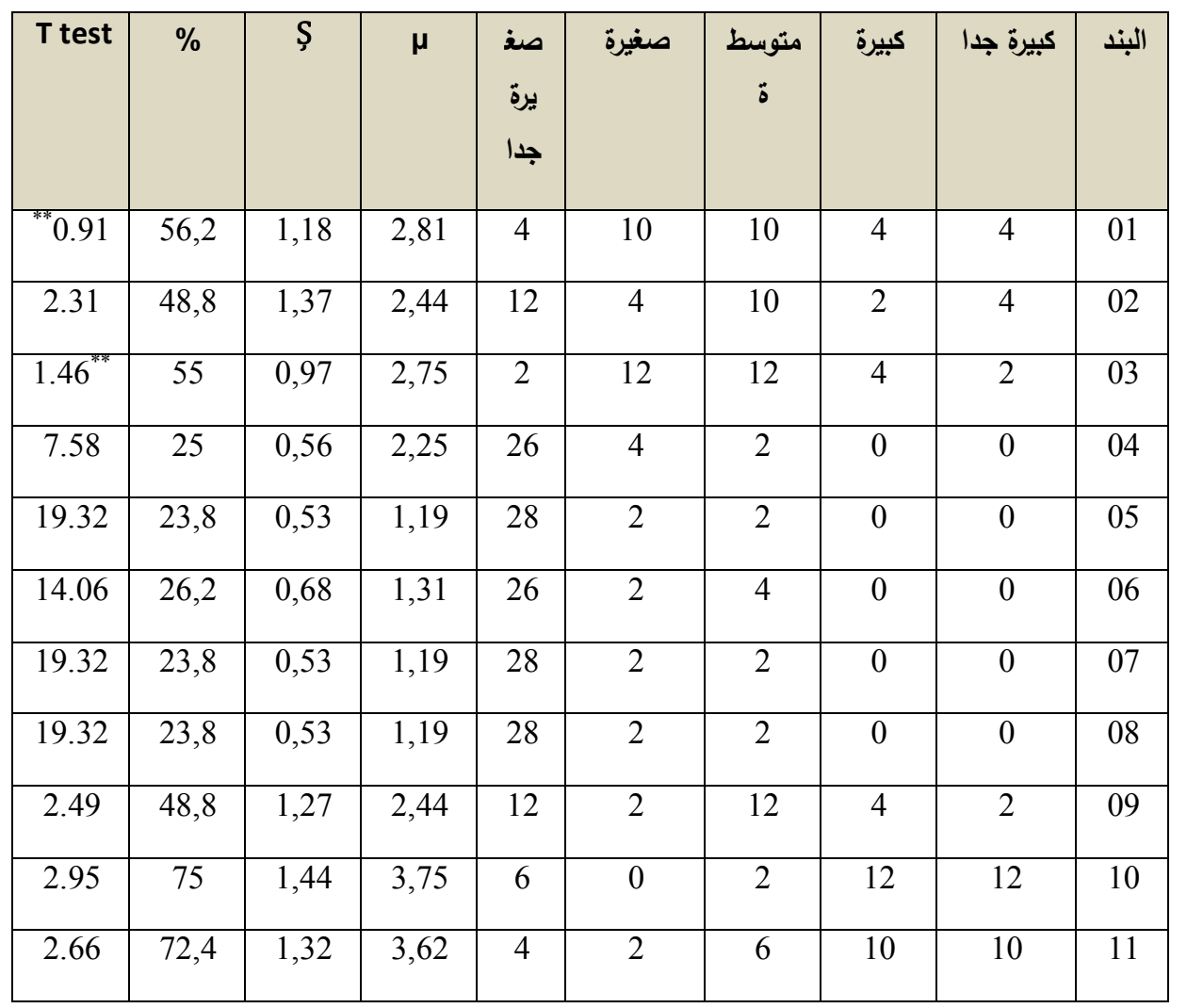




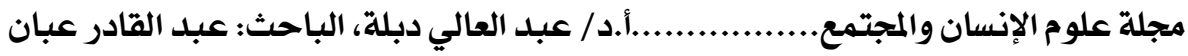

\begin{tabular}{|c|c|c|c|c|c|c|c|c|c|}
\hline 0.98 & 55 & 1,44 & 2,75 & 10 & 4 & 6 & 8 & 4 & 12 \\
\hline 3.15 & $\mathbf{4 4 , 4}$ & $\mathbf{1 , 4}$ & $\mathbf{2 , 2 2}$ & \multicolumn{5}{|c|}{ المتوسط العام للمحور ككل } \\
\hline
\end{tabular}

يتبين لنا من خلال النتائج المتحصل عليها من بنود المحور الثالث أن المتوسط العام لهذا المحور = 2,22 مما يدل أن درجة وعي المواطنين منخفضة حول الإدارة

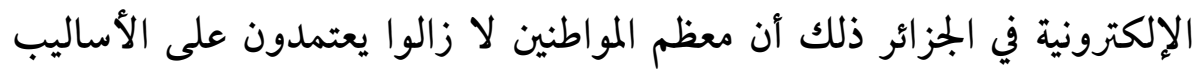
التقليدية في إقتناء حاجاتهم الخدماتية من البلدية .

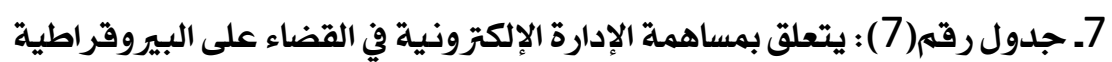

\begin{tabular}{|c|c|c|c|c|c|c|c|c|c|}
\hline$T$ test & $\%$ & Ș & $\mu$ & صنا & صغيرة & $\begin{array}{c}\text { متوسط } \\
\text { متط }\end{array}$ & كبيرة & كبيرة & البند \\
\hline 59.07 & 96,2 & 0,39 & 4,81 & 0 & 0 & 0 & 30 & 132 & 01 \\
\hline 11.26 & 81,4 & 1,21 & 4,07 & 6 & 18 & 24 & 24 & 90 & 02 \\
\hline 11.07 & 80 & 1,15 & 4 & 6 & 18 & 18 & 48 & 72 & 03 \\
\hline 28.13 & 87,4 & 0,62 & 4,37 & 0 & 0 & 12 & 78 & 72 & 04 \\
\hline 13.72 & 82,2 & 1,03 & 4,11 & 6 & 0 & 42 & 36 & 78 & 05 \\
\hline 9.03 & 75,6 & 1,1 & 3,78 & 0 & 30 & 30 & 48 & 54 & 06 \\
\hline 12.59 & 78,6 & 0,94 & 3,93 & 0 & 12 & 42 & 54 & 54 & 07 \\
\hline 20.64 & 86,6 & 0,82 & 4,33 & 0 & 6 & 18 & 54 & 84 & 08 \\
\hline${ }^{* *} 0.95$ & 62,2 & 1,47 & 3,11 & 36 & 18 & 42 & 24 & 42 & 09 \\
\hline 34.83 & 91,2 & 0,57 & 4,56 & 0 & 0 & 6 & 60 & 96 & 10 \\
\hline 12.73 & 80,8 & 1,04 & 4,04 & 6 & 6 & 30 & 54 & 66 & 11 \\
\hline 12.08 & 82,2 & 1,17 & 4,11 & 12 & 0 & 30 & 36 & 84 & 12 \\
\hline 10.90 & 81,4 & 1,25 & 4,07 & 12 & 6 & 30 & 24 & 90 & 13 \\
\hline 21.27 & 87,4 & 0,82 & 4,37 & 0 & 0 & 36 & 30 & 96 & 14 \\
\hline 14.48 & 83,2 & 1,02 & 4,16 & \multicolumn{6}{|c|}{ لمتوسط العام للمحور ككل } \\
\hline
\end{tabular}


يتبين لنا من خلال النتائج المتحصل عليها من بنود المحور الرابع أن المتوسط العام

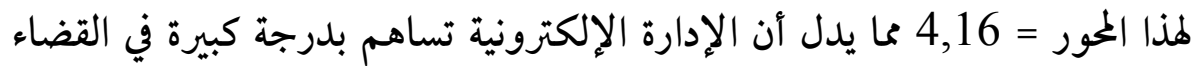
على البيروقراطية الإدارية المتفشية في البلديات الجزائرية. 10ـ إختبار فرضيات الدراسة : 1ـ تنص الفرضية الفرعية الأولى على أن هناك إمكانية كبيرة لتطبيق الإدارة

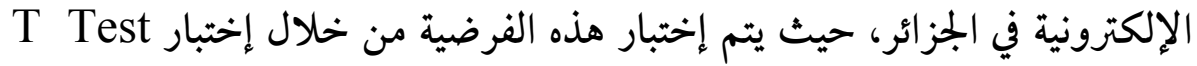
كما يلي :

\begin{tabular}{|c|c|c|c|c|}
\hline القرار الإحصائي & مستوى المعنوية & حجم العينة & $\begin{array}{l}\text { T Test } \\
\text { الجدولية }\end{array}$ & $\begin{array}{c}\text { T Test } \\
\text { المحسوية }\end{array}$ \\
\hline نقبل HO & $0,05=\alpha$ & 162 & 1.654 & 1.403 \\
\hline
\end{tabular}

ومنه فإنه يمننا قبول الفرض الصفري ورفض الفرض البديل، آي أنه ليست هناك إمكانية كبيرة لتطبيق الإدارة الإلكترونية في الجزائر . 2. تنص الفرضية الفرعية الثانية على أن الإدارة الإلكترونية تساهم بدرجة كبيرة

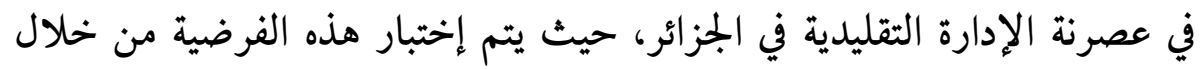
إختبار Test T Tما عيلي:

\begin{tabular}{|c|c|c|c|c|}
\hline القرار الإحصائي & مستوى المعنوية & حجم العينة & $\begin{array}{l}\text { T Test } \\
\text { الجدولية }\end{array}$ & $\begin{array}{l}\text { T Test } \\
\text { المحسوبة }\end{array}$ \\
\hline نرفض H0 & $0,05=\alpha$ & 162 & 1.654 & 13.208 \\
\hline
\end{tabular}

ومنه فإننا نرفض الفرض الصفري ونقبل الفرض البديل الذي ينص على أن الإدارة الإلكترونية تساهم بدرجة كبيرة في عصرنة الإدارة التقليدية في الجزائر. 
مجلة علوم الإنسان والمجتمع............................... عبد العالي دبلة، الباحث: عبد القادر عبان

3. تنص الفرضية الفرعية الثالثة على أن هناك علاقة إرتباطية بين درجة تطبيق

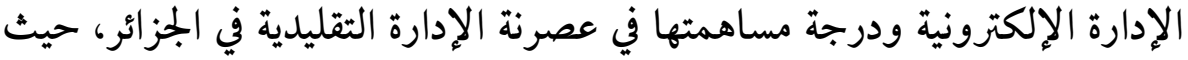
يتم إختبار هذه الفرضية من خلال معامل بيرسون للإرتباط كما يلي:

\begin{tabular}{|c|c|c|c|c|c|}
\hline الإحصائي & $\begin{array}{l}\text { T Test } \\
\text { الجدولية }\end{array}$ & $\begin{array}{l}\text { T Test } \\
\text { المحسوبة }\end{array}$ & مستوى المعنوية & الحرية & بيرسون \\
\hline دال إحصائيا & 1,96 & -6.37 & $0,05=\alpha$ & 160 & -0.45 \\
\hline
\end{tabular}

يبين معامل بيرسون أن هناك علاقة عكسية متوسطة بين درجة تطبيق

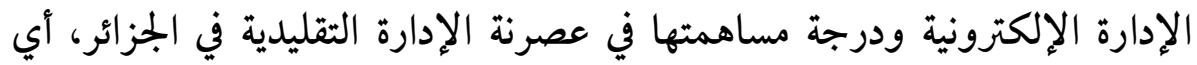

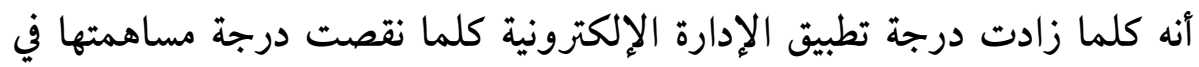

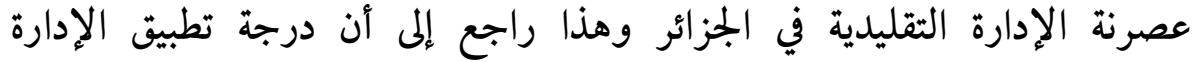

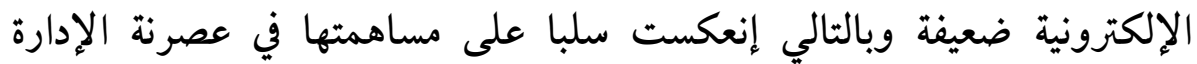

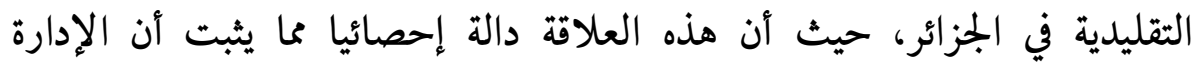

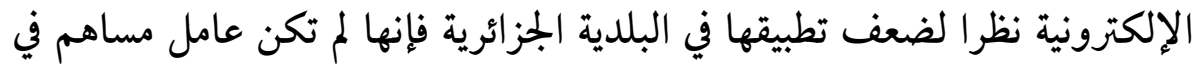

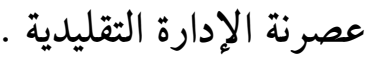

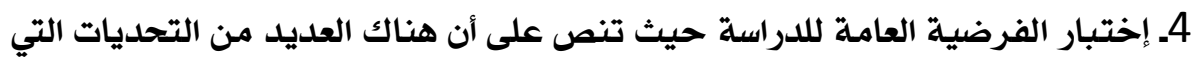
تواجهها الإدارة الإلكترونية في الجزائر من خلال إختبار ذي الحئ الحدين كما يلي :

\begin{tabular}{|c|c|c|c|c|c|}
\hline المعنوية & العينة & Z الجدولية & Z المحسوبة & لا توديات & تحديات \\
\hline $0,05=\alpha$ & 194 & 1,96 & 9,33 & 32 & 162 \\
\hline
\end{tabular}

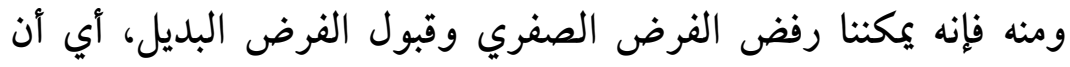

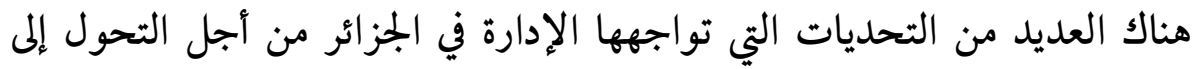

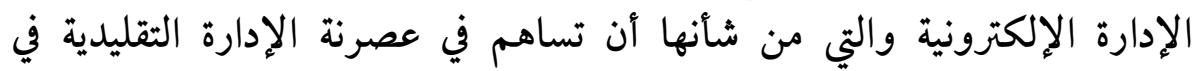
الجزائر الإدأرة 
11 11

من خلال ما سبق نستتج أن الإدارة الإلكترونية في الجزائر تواجهها العديد من التحديات نذكر منها :

1. ضعف البنية التحتية المادية والمالية لبناء الإدارة الإلكترونية في الجزائر .

2. نقص اليد العاملة المؤهلة والكفوءة في الإدارات الجزائرية .

3. نقص الوعي الإلكتروني لدى المواطن الجزائري فيما يخص التعاملات

الإلكترونية

4. غياب التشريعات والقوانين التي تنظم عمل الإدارة الإلكترونية في

الجزائر. 


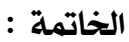

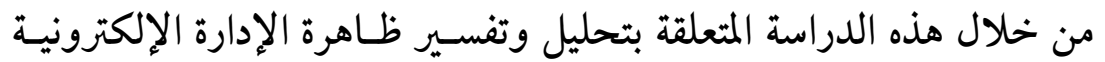

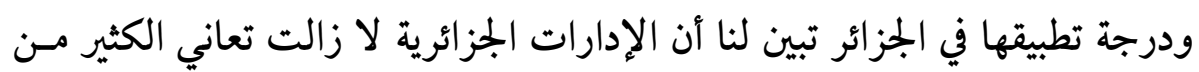

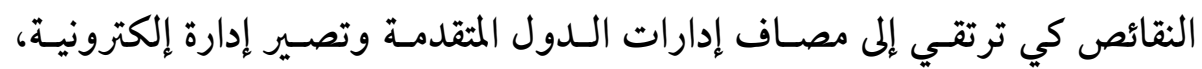

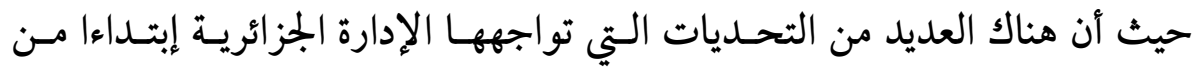

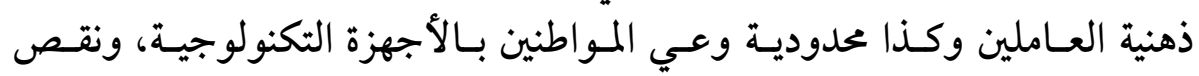

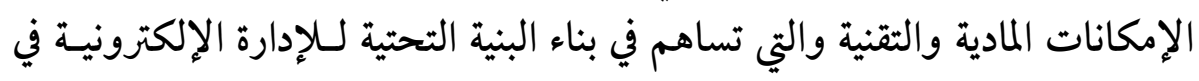

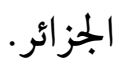




\section{هوامش البحث:}

(1) سليمان محمد الطماوي: الوجيز في القانون الإداري، مكتبة جامعة عين شمس، مصر، 1985، ص 46

(2) الصغير محمد: قانون الإدارة المحلية الجزائرية، دار العلوم للنشر والتوزيع، عنابة، الجزائر، 2004، ص 139.

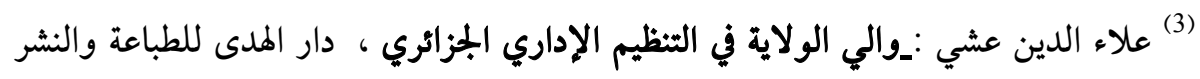

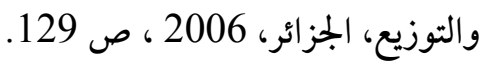
(4) العمري بوحيط: البلدية (إصلاحات، مهام واساليب )، شركة زاعياش للطباعة والنشر،

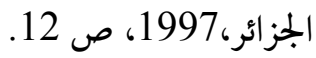
(5 ممد محمود الخالدي : التكنولوجيا الإلكترونية، دار كنوز المعرفة للنشر والتوزيع، عمان

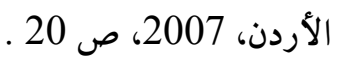

